\title{
STUDIES OF DISSIPATION PATTERN OF CYPERMETHRIN IN TOMATO
}

NILUFAR NAHAR*, MOHAMMAD SHOEB, M IQBAL ROUF MAMUN, SULTAN AHMED $^{1}$, MIR MAHADI HASAN AND AHMEDUL KABIR

Department of Chemistry, University of Dhaka, Dhaka-1000, Bangladesh

${ }^{1}$ Bangladesh Agricultural Research Institute (BARI), Gazipur, Dhaka-1000, Bangladesh

Abstract

Dissipation pattern of cypermethrin (Ripcord 10EC) on tomato plants sprayed at recommended and double the recommended doses followed first order kinetics. In both the doses residues were found below the maximum residue level $(0.5 \mathrm{ppm})$ after one day of application. Recoveries were found to be $80.88 \%$ \&77.09\% spiked at $0.2 \& 0.5 \mathrm{ppm}$, respectively. LOD and LOQ were found to be 0.01 and $0.06 \mathrm{ppm}$, respectively.

\section{Introduction}

Cypermethrin, a non-systemic insecticide, acts on the nervous systems of the insect and is widely used in cotton, fruits, tobacco, rice and vegetables, potatoes, tomatoes etc. for pest control. ${ }^{1,2}$ The tomato fruit (Lycopersicon esculentum) is one of the important vegetables for human diet which is rich in antioxidant molecules and contribute to human health. ${ }^{3}$ Vegetables are usually susceptible to pest attack and different kinds of pesticides are being used in cultivation around the world including Bangladesh. Use of pesticide is necessary to increase crop production. However, indiscriminate use of insecticides and without maintaining the proper pre-harvest interval can make the food unsafe, especially when tamotoes are used as salad. We earlier reported about residues of ripening agent (ethephon) in tomato fruits. ${ }^{4}$ In this paper, we are now reporting the dissipation pattern of cypermethrin and safe harvesting period of the fruits.

\section{Materials and methods}

\section{Field experiment and sampling}

Tomato was grown in the experimental field of Entomology Division, Bangladesh Agricultural Research Institute (BARI), Joydebpur, Gazipur, Dhaka. Commercial grade cypermethrin (Ripcord 10EC) was sprayed on whole plant of tomatoes grown in the experimental plot ( $3 \mathrm{~m} \times 4 \mathrm{~m})$ at recommended $(1 \mathrm{~mL} / \mathrm{L}$ in water) and double the recommended doses ( $2 \mathrm{~mL} / \mathrm{L}$ in water). One plot was kept untreated for control sample collection. Three replicate treated samples and one control sample were collected at 0 (2 hours after spraying), 1, 3, 5, 7, 10 and 15 days after application of cypermethrin during February-March 2009. Collected samples (150-250 g) were packed in Jip-lock polyethylene bags, labeled and immediately kept in Chill box to transfer to the Department of Chemistry, University of Dhaka and stored at $-20^{\circ} \mathrm{C}$ until analysis.

* To whom correspondences may be made; e-mail: nilufarnahar@yahoo.com 


\section{Reagents and Chemicals}

The analytical standard cypermethrin (purity 98.5\%) was purchased from Dr. Ehrenstrofer GmbH, Augsberg-Germany. Florisil was purchased from Sigma Aldrich, USA. Anhydrous sodium sulfate, extra pure analytical grade ethyl acetate (EtOAc), dichloromethane (DCM) and n-hexane were purchased from Merck, Germany.

\section{Instruments}

Gas chromatographic (GC) analyses were performed using a Shimadzu-2010 machine fitted with an electron capture detector (ECD) having split/splitless auto injector. Injector and detector temperatures were set at $280^{\circ} \mathrm{C}$ and $290^{\circ} \mathrm{C}$, respectively. Separations were performed on a HP-5 capillary column $\left(30 \mathrm{~m} \times 0.25\right.$ i.d.) at $120^{\circ} \mathrm{C}$ to $270^{\circ} \mathrm{C}$ with a rise $10^{\circ} \mathrm{C} / \mathrm{min}$. Nitrogen was used as carrier and make-up gas with a flow rate of 1.78 $\mathrm{mL} / \mathrm{min}$.

Gas chromatography-mass spectrometry (GC-MS) analyses were carried out using an Agilent 6890 series GC coupled with a 5973 mass selective detector (MSD) (Agilent Technologies, Wilmington, DE) having auto injector and auto sampler. Separations were accomplished using a capillary column HP-5MS $30 \mathrm{~m}$ (30 $\mathrm{m} \times 0.25$ i.d.) in scan mode at $120^{\circ} \mathrm{C}$ for $1 \mathrm{~min}$, raised $10^{\circ} \mathrm{C} / \mathrm{min}$ till $200^{\circ} \mathrm{C}$ and $5^{\circ} \mathrm{C} / \mathrm{min}$ till $280^{\circ} \mathrm{C}$ using helium as the carrier gas.

\section{Extraction and clean up of samples}

Tomato samples of each day were homogenized and divided into three parts for three replicate studies. Each sample $(50 \mathrm{~g})$ was thoroughly mixed with anhydrous sodium sulphate (60 g) by mortar and pestle and then extracted with ethyl acetate $(100 \& 20 \mathrm{~mL})$. The ethyl acetate extract was filtered, dried completely and was redissolved in n-hexane $(1 \mathrm{~mL})$ for clean up.

Clean up was carried out by a column using florisil (12 g, lower part) and neutral alumina (5 g, upper part) in n-hexane. The extract $(1 \mathrm{~mL})$ was applied to the column and eluted with $\mathrm{n}$-hexane $(50 \mathrm{~mL})$ followed by dichloromethane $(100 \mathrm{~mL})$. The hexane part was discarded and DCM part was then evaporated to dryness, redissolved in n-hexane and adjusted the volume to $1 \mathrm{~mL}$ for GC analysis.

\section{Recovery}

Control tomato samples (50.0 g) was spiked with standard cypermethrin solution at two different levels ( 0.2 and $0.5 \mathrm{ppm}$ ), and were extracted and cleaned up following the same procedure as described above.

\section{Results and Discussion}

The residual level of cypermethrin in tomato fruits was analyzed by GC-ECD using external standard calibration method. Cypermethrin showed a group of four sharp and symmetrical peaks which were confirmed by GC-MSD. The efficacy of the extraction and clean up procedure was evaluated by performing triplicate recovery experiments at 
two different spiking levels of cypermethrin and were found to be $80.88 \%$ when spiked at $0.2 \mathrm{ppm}$ and $77.09 \%$ spiked at $0.5 \mathrm{ppm}$. LOD (limit of detection) and LOQ (limit of quantification) were calculated as 0.01 (Signal to noise ration, 3:1) and 0.06 (S/N, 10:1) ppm, respectively.

Residual amounts of cypermethrin in all the analyzed samples sprayed at both doses are presented in Table 1. The results showed when cypermethrin was sprayed at recommended dose, a residue level of $0.29 \mathrm{ppm}$ at zero day followed by $0.24 \mathrm{ppm}$ at 1 day and gradually declined to $0.07 \mathrm{ppm}$ at 10 days and no residue was found after 15 days above the quantification limit. This showed excellent similarity with the result obtained by Qiankai \& Guonian $(1985)^{5}$ where cypermethrin 10 EC was sprayed on matured tomatoes and residue was found to be below $0.20 \mathrm{ppm}$ on the first day of spraying. All the residual values were lower than the maximum residue limit (MRL) of $0.5 \mathrm{ppm}$ for cypermethrin recommended by Codex Alimentarius Commission ${ }^{6}$. In case of double the recommended dose, residue was found to be $0.55 \mathrm{ppm}$ at zero day which was slightly higher than the MRL value and was reduced to below MRL value $(0.45 \mathrm{ppm})$ the following day ( 1 day) and declined to $0.01 \mathrm{ppm}$ after 15 days of spraying.

\section{Table 1. Residual cypermethrin in tomato samples}

\begin{tabular}{lll}
\hline Time interval (days) & Residual cypermethrin in ppm (Mean \pm SD) \\
\hline & Double of the recommended dose & Recommended dose \\
\hline 0 & $0.55 \pm 0.02$ & $0.29 \pm 0.02$ \\
1 & $0.45 \pm 0.10$ & $0.24 \pm 0.03$ \\
3 & $0.38 \pm 0.12$ & $0.20 \pm 01$ \\
5 & $0.26 \pm 0.05$ & $0.15 \pm 01$ \\
7 & $0.19 \pm 0.08$ & $0.11 \pm 01$ \\
10 & $0.10 \pm 0.08$ & $0.07 \pm 0.03$ \\
15 & $0.01 \pm 0.006$ & BQL \\
\hline
\end{tabular}

$\mathrm{BQL}=$ Below Quantification Limit
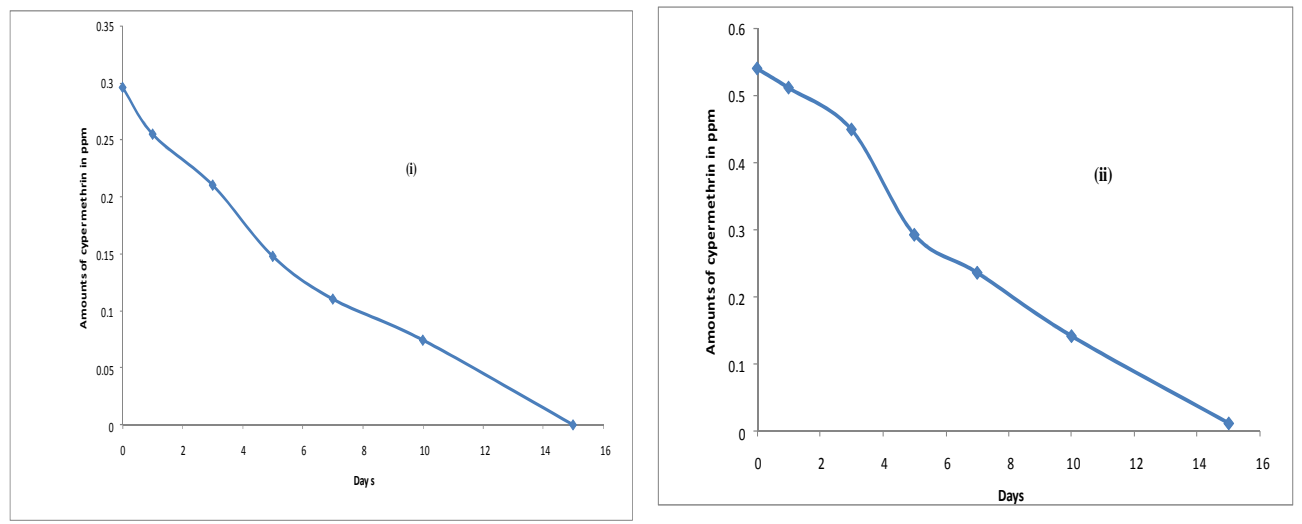
Fig. 1. Graphical presentation of dissipation pattern of cypermethrin in tomato fruits; (i) with recommended dose, (ii) with double the recommended dose

Dissipation of cypermethrin in tomato samples after pesticide application followed first order kinetics at recommended and double the recommended doses, respectively (Figure 1: i.\& ii). The results are in agreement with the findings of Chai et al (2009) ${ }^{7}$ where dissipation of cypermethrin was studied in green mustard and soil in a humid-tropical vegetable production system.

Any pesticide including cypermethrin should get registration eligibility for using in a particular country both for agricultural and non-agricultural purposes after conducting human health and ecological risk assessment with positive results. ${ }^{8}$ Since the MRL value of cypermethrin is $0.5 \mathrm{ppm}$ and obtained less than this level even after 1 day of application, we suggest that pre-harvest interval for tomatoes after application of cypermethrin should be at least two days.

\section{Acknowledgments}

The authors are grateful to International Programme in the Chemical Sciences (IPICS), Uppsala, Sweden for financial support.

\section{References}

1. The Pesticide Manual, Fourteen Edition, Editor: C D S Tomlin, British Crop Production Council, 2006.

2. M. Abdullah, O. Sarnthoy and S. Kasetsart, J. Nat. Sci., 2001, 35: 115-121.

3. G. Gambacorta, M. Faccia,. C. Lamacchia, A. Di. Luccia and E. La. Nottee, Food Control, 2005, 16, 629.

4. T. Rob, S. Mandal, M.I.R Mamun, N. Nahar, M. Mosihuzzaman and M.S. Ahmed, Journal of Bangladesh Chemical Society, 2007, 20 (1). 206-209.

5. L. Qiankai and Z. Guonian, Journal of Zhejiang Agricultural University, 1985, 02.

6. ANON. Codex Alimentarius. Pesticide Residues in Food. Volume 2. Second edition. FAO/WHO, Rome, Italy, 1993 p. 3 - 4; p. 461 - 462

7. L. K. Chai, N. Mohd-Tahir and H. C. B. Hansen, Pest Management Science, 2009, 65 (2), 189-196.

8. D. Edwards; "Registration Eligibility Decision (RED) for Cypermethrin, EPA”, List B, Case No. 2130, June, 2006.

(Received : 12 June, 2012; Accepted : 13 November, 2012) 